\title{
Design and Performance Measurement of a Miniaturized Implantable PIFA Antenna for Biomedical Applications
}

\author{
Nasim Al Islam and Farhadur Arifin
}

\begin{abstract}
An implantable PIFA (Planar Inverted F Antenna) antenna for biomedical applications is proposed in this study. The main notability of this design refers to its subtle dimension, flexibility and subordinate thickness that makes it perfectly suitable for implementing inside human or animal tissues for Wireless Body Area Networks (WBAN). The antenna is aimed to operate in the Industrial, Scientific and Medical (ISM) band (2.4$2.4835 \mathrm{GHz}$ ). The thickness of this antenna is only $0.735 \mathrm{~mm}$, which implies that this antenna is suitable to perform under bent conditions. The antenna offers a compact design with a dimension of $9.48 \mathrm{~mm} \times 7.8 \mathrm{~mm} \times .735 \mathrm{~mm}\left(54.348 \mathrm{~mm}^{3}\right)$. Copper and Rogers R03010 are chosen as the patch material and substrate material accordingly. The antenna is encapsulated inside biocompatible material Rogers $\mathbf{R 0 3 0 1 0}$ for safety concern inside skin or muscle tissues. Several types of analysis and performance measurement of this antenna have been done by using CST Microwave studio in both planar and bent conditions by maintaining the electrical properties of human skin tissues. Specific Absorption Rate (SAR) and thermal loss are evaluated to comply with the antenna safety issues. For proving biocompatibility and versatility of this antenna, performance analysis by changing different patch materials and substrate materials have been done after putting the antenna inside different human tissue models. Finally, the antenna is fabricated on to a FR4 substrate and its performance is measured using Agilent Technologies E5071C Network Analyzer.
\end{abstract}

Keywords-PIFA; ISM Band; Implantable Antenna; Human Body Model;

\section{INTRODUCTION}

Implantable devices have been developed enough to enhance patients nursing quality and to affirm patients safety now a days. In this modern era, it is impossible for most patients to afford long-term hospital stays due to financial confinements, work and other reasons, even though their health status must be monitored in a real-time or short periodic time mode. In order to keep pace with the technological advancement in healthcare sector, remote diagnostic systems

\footnotetext{
Nasim Al Islam

Lecturer of the Department of EEE

American International University-Bangladesh (AIUB)

Dhaka, Bangladesh

e-mail: nasim.islam.bd@ieee.org
}

can play emergent role by coordinating with wireless communication technology. Thus, implantable antenna is becoming a vital part of portable medicinal devices focusing on real-time monitoring [1].

Miniaturization is a key challenge to be proficient for implantable medical devices in the human body. For designing implantable antenna, variation of electromagnetic properties in the vicinity of human tissue is to be considered. These properties alter the antenna characteristics such as resonance frequency and impedance matching [2-3]. It is also necessary to encapsulate the antenna with biocompatible material to ensure the protection of human tissue from radiation [4].

Wireless Body Area Network (WBAN) provides connectivity between different nodes of body with the help of sensors or antenna to a remote health monitoring system through wireless communication channel. WBANs supporting healthcare applications are in early development stage but offer important commitments at monitoring, diagnostic and therapeutic levels. With the use of RF technology, data recorded by the implanted antenna can be transmitted wirelessly to the receiving end which results in an effective healthcare monitoring system. However, in this structure, the data exchange capability is limited and the range between internal and external system is confined. Also in practical cases, for establishing communication of WBAN via implantable antenna is always a tough task due to the miniaturized size of biomedical devices and noisy surrounding environment [5]. This is where the main motive of this research work comes in.

For the communication of biomedical antenna, several bands are mostly considered like Wireless Medical Telemetry Service (WMTS), Medical Implant Communication Service (MICS) and Industrial, Scientific and Medical (ISM). Wide variety of frequencies offered by these bands facilitate the significant advances in wireless medical technologies. ISM band has been chosen for our work due to its flexibility to work with gigahertz range frequency bandwidth, which allows to reduce the wavelength [6-7].

With the revolutionary development in the field of biomedical implants like cardiac defibrillators [8-10], cochlear implants and brain neurostimulators [11] etc. can be easily manipulated by using RF technology. Recent researches in the design of implantable antennas cover several factors like size 
reduction, bending capability, bandwidth requirement, SAR evaluation, biocompatibility, radiation and coupling effects [12]. Through continuous improvement of reliability issues and miniaturized dimension, revolution in implantable biomedical devices sector is speeding up day by day. The proposed antenna in this context can offer valuable contribution in biomedical and healthcare applications. One of the key features of this antenna is its miniscule dimension with proper evaluation of safety issues.

Specially PIFA antenna has been used for this research work due to its flexibility of shortening the overall antenna length through shorting pin. PIFA antenna is widely used in compact hand-held wireless devices where space shortage is the main factor. Now a days, PIFA antenna is gaining important considerations in different biomedical applications. Several related research shows biomedical applications of this type of antenna in WMTS, ISM and MICS band [13-16].

The orientation of this paper is described as follows. In Section II, modeling and design procedure of the antenna is narrated. In Section III, several parameters of the antenna have been calculated and analyzed for both planar and bend condition. In Section IV \& V, antenna fabrication with result \& comparison in different context is demonstrated to prove the versatility of this antenna. Finally, Section VI covers the concise summary of this work.

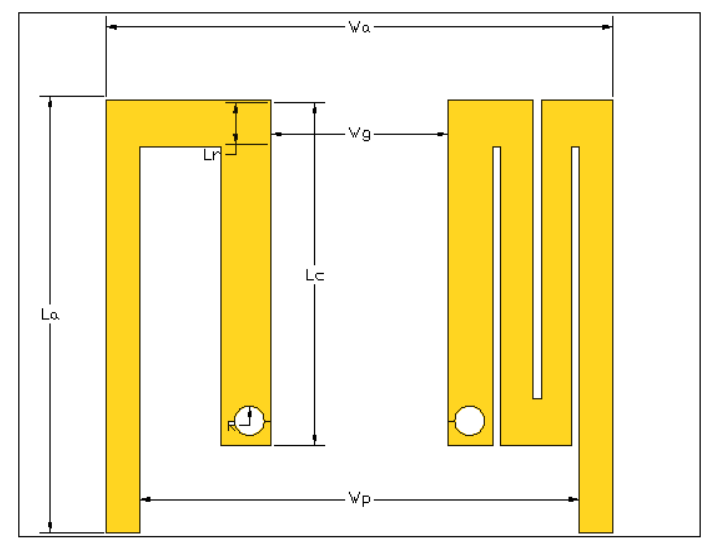

(a)

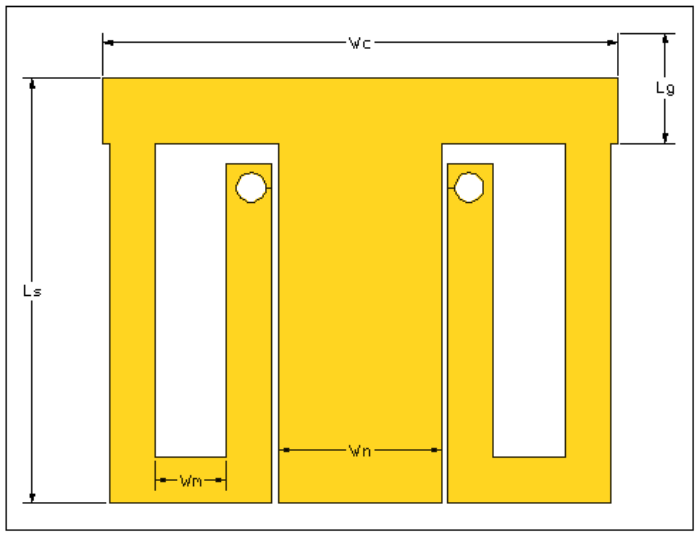

(b)

Fig. 1. Model of the Antenna: (a) Top layer; (b) Bottom layer

\section{MODELING OF THE ANTENNA}

In this paper, a flexible rectangular patch shaped miniaturized antenna is designed for different biomedical applications. Configuration of this antenna is mainly based on PIFA type. In order to make antennas suitable for in body applications, there are two major issues that need to be considered: miniaturization and biocompatibility. Shrinking the dimension of the ground plane and placing radiating material on both sides of the substrate material, size reduction is achieved. The entire antenna was encapsulated by biocompatible material Rogers R03010 for maintaining the safety regulations properly. For designing this antenna, Rogers R03010 is used as the substrate material which has a dielectric constant of 10.2, $\tan \delta$ of 0.0035 and thickness of $0.635 \mathrm{~mm}$. This kind of low thickness of antenna proves its flexibility to bend as well as reduces the total electric size of the antenna. Copper with a thickness of $0.1 \mathrm{~mm}$ is used as the patch and ground material for lessening the cost as well as due to its availability. Meandering slots were cut according to the current distribution to keep the antenna working accurately under ISM Band. ISM band allows the diversity for shortening the wavelength with a high bit rate [17-18].

\section{A. Geometry of the antenna}

The entire antenna is wrapped by a superstrate material of Rogers R03010 which prevents direct contact between radiating material with human skin tissue and also acts as a buffer between these two layers for lessening the radiation loss inside human tissue [19]. Fig. 1 shows the top and bottom layers of the antenna with their size parameters. The whole antenna was designed and simulated inside human skin tissue model using CST Microwave Studio. Final geometrical size of this antenna is $9.48 \mathrm{~mm} \times 7.8 \mathrm{~mm} \times .735 \mathrm{~mm}\left(54.348 \mathrm{~mm}^{3}\right)$.
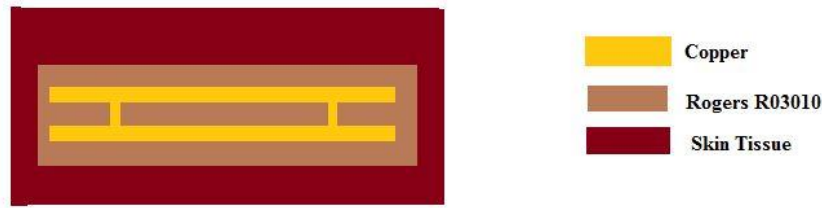

Fig. 2. Cross-sectional view of one layer skin model geometry of the antenna

In Fig. 2, the antenna in the vicinity of human skin tissue is presented for a better understanding of the placement of antenna.

Certain equations have been used to calculate the length and width of the patch and ground of antenna for getting the resonant frequency at ISM Band. By monitoring the current density at the patch or radiating material several slots were cut. Equation for the PIFA (if the width of the radiating patch is not equal to the width of the shorting pin) is given below [20]:

$$
f_{R}=l_{1}+l_{2}+h+W_{C}=\frac{\lambda_{0}}{3}
$$

Where $l_{1} \& l_{2}$ is length and width of the radiating patch, $h$ is the height of the patch from the ground plane. The resonant frequency of the antenna can be computed using the following equation [25],

$$
L_{2}+H=\frac{\lambda_{0}}{4}
$$

TABLE I. SUMMARIZES THE ANTENNA SIZE PARAMETERS.

\begin{tabular}{|l|l|l|l|}
\hline Parameter & Size $(\mathrm{mm})$ & Parameter & Size $(\mathrm{mm})$ \\
\hline
\end{tabular}




\begin{tabular}{|c|c|c|c|}
\hline$W a$ & 9.240 & $R$ & 0.270 \\
\hline$L a$ & 7.862 & $W c$ & 9.480 \\
\hline$W g$ & 3.240 & $L s$ & 7.800 \\
\hline$W p$ & 8.040 & $W m$ & 1.320 \\
\hline$L c$ & 6.178 & $W n$ & 3.000 \\
\hline$L n$ & 0.737 & $L g$ & 2.0278 \\
\hline
\end{tabular}

\section{B. Material specification}

For designing the antenna, Copper and Rogers R03010 have been used as the patch material and substrate material accordingly. The specification of the materials are given below in Table II and III. [21]

TABLE II. ELECTRICAL PROPERTIES OF COPPER

\begin{tabular}{|c|c|}
\hline Parameters & Values \\
\hline Loss Tangent, tan $\delta$ & 0.025 \\
\hline
\end{tabular}

TABLE III. ELECTRICAL PROPERTIES OF ROGERS R03010

\begin{tabular}{|c|c|}
\hline Parameters & Values \\
\hline Dielectric Constant, $\varepsilon_{\mathrm{r}}$ & 10.2 \\
\hline Loss Tangent, $\tan \delta$ & 0.0035 \\
\hline
\end{tabular}

Table IV visualizes the dielectric properties like permittivity and conductivity of the human skin tissue which needs to be maintained according to the operating frequency of the antenna. [22]

TABLE IV. DIELECTRIC VALUES OF HUMAN SKIN TISSUE AT DifFERENT FREQUENCIES

\begin{tabular}{|c|c|c|}
\hline Frequency $(\mathbf{G H z})$ & $\boldsymbol{\varepsilon}_{\boldsymbol{r}}$ & $\boldsymbol{\sigma}(\mathbf{S} / \mathbf{m})$ \\
\hline 2.0 & 39.29 & 1.45 \\
\hline 2.4 & 38.79 & 1.70 \\
\hline $\mathbf{2 . 4 5}$ & $\mathbf{3 8}$ & $\mathbf{1 . 4 6}$ \\
\hline 2.5 & 37.66 & 1.77 \\
\hline 3.0 & 37.05 & 2.14 \\
\hline
\end{tabular}

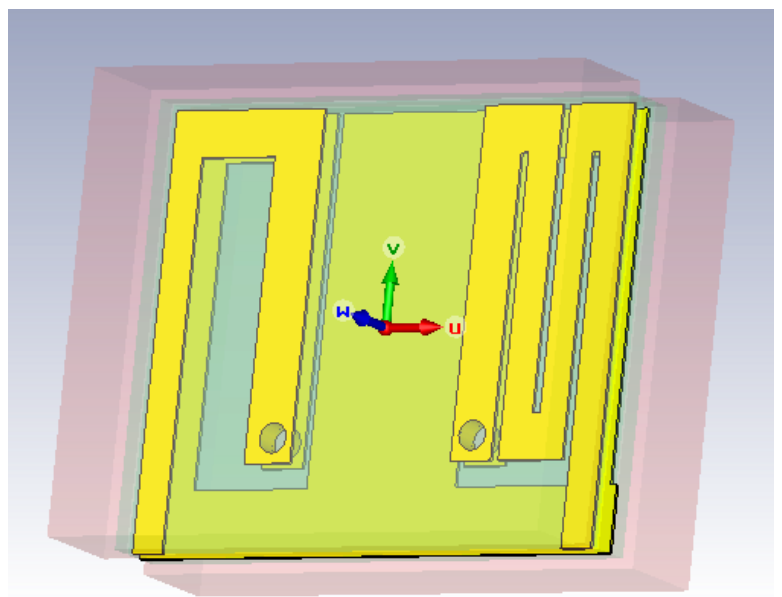

Fig. 3. Antenna inside Skin Tissue Model

\section{Simulated ReSUlts}

Several antenna parameters were simulated for strengthening the reliability of the antenna for biomedical applications. The antenna performance was measured inside human skin tissue model where the encapsulated antenna is immersed inside the skin bio tissue of thickness $2.682 \mathrm{~mm}$ at CST Microwave Studio simulation environment. Fig. 3 shows the antenna inside the skin tissue model.

\section{A. S11 parameter}

Fig. 4 demonstrates the S11 parameter of the antenna inside skin tissue model. S11 parameter or reflection coefficient of an antenna exhibits the amount of power which is being radiated from the antenna. It can be seen from Fig. 4 that the antenna has a resonant frequency $2.48 \mathrm{GHz}$ with a return loss of $17.81 \mathrm{~dB}$ which satisfies the ISM band. The bandwidth of the antenna is around $198.4 \mathrm{MHz}$.

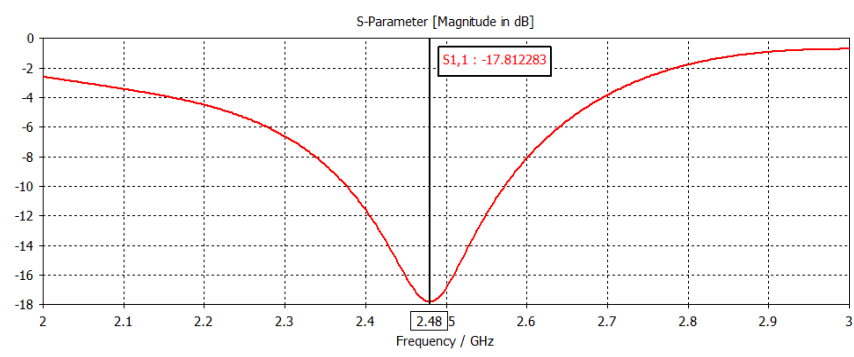

Fig. 4. S11 parameter of the antenna inside Skin Tissue Model

\section{B. Voltage Standing Wave Ratio (VSWR)}

The parameter VSWR is a measure that numerically describes how well the antenna is impedance matched to the radio of transmission line it is connected to. In general, a VSWR of less than 2 is considered to be a very good value. As seen from Fig. 5, the VSWR of our antenna at resonant frequency was well below the 2 mark.

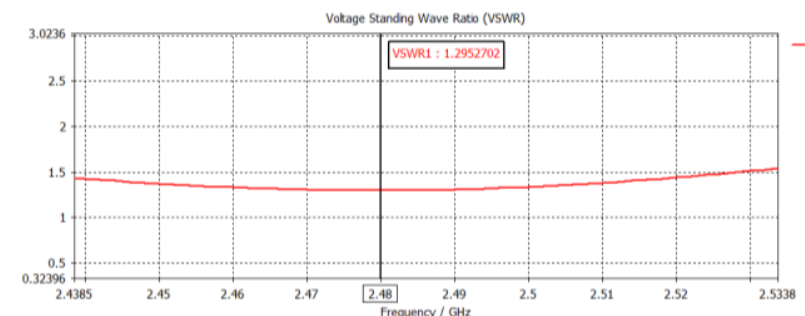

Fig. 5. VSWR plot of the antenna inside Skin Tissue model

\section{Far field radiation pattern}

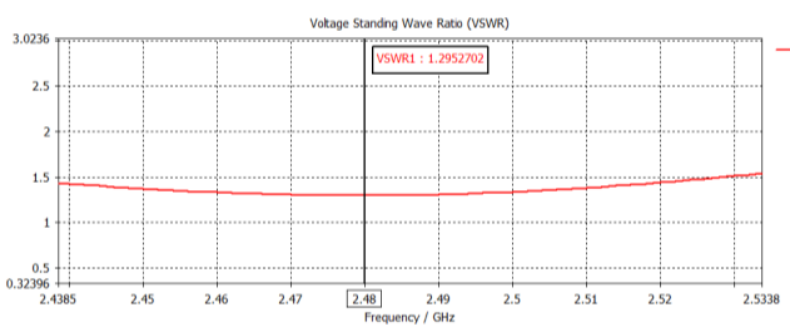

Fig. 6. 3D view of Far-Field Region of the antenna inside Skin Tissue Model

Radiation characteristics of the antenna can be manipulated from 3D and 2D view of the Far-Field radiation pattern. From Fig. 6 it is observed that the antenna has a directivity of 2.952 dBi. Fig. 7 visualizes that the antenna has its main lobe magnitude of $2.95 \mathrm{dBi}$ centered at 111 degree and the angular width is around 124.5 degree. The maximum gain of the antenna is $-28.898 \mathrm{dBi}$ at $\theta=75$ degree and $\varphi=90$ degree which denotes that the antenna is radiating maximum radio frequency energy on that angle. 


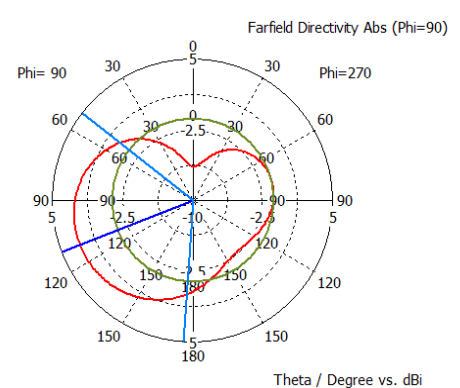

Fig. 7. 2D view of Far-Field Region of the antenna inside Skin Tissue Model

\section{Performance under bending condition}

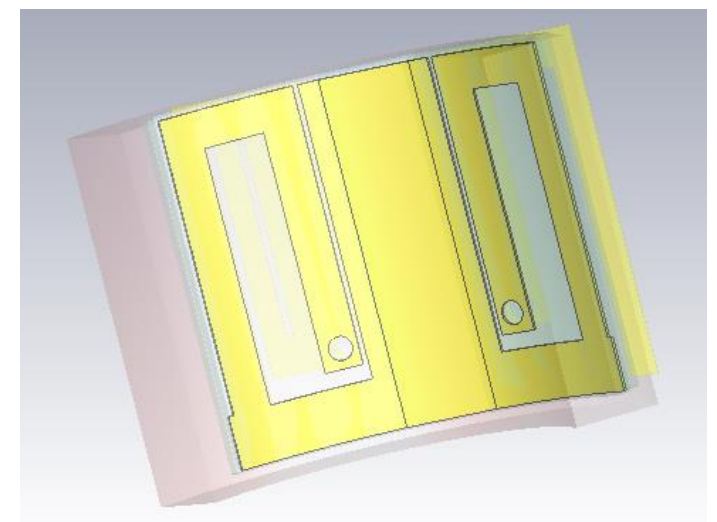

Fig. 8. Antenna undergoing Bent Test inside Skin Tissue Model

As this antenna is subjected to work inside the body, it should work perfectly under bent condition as there are many curvature in human body. Fig. 8 shows the antenna in bent condition when the antenna is convexed around the $\mathrm{x}$-axis around a $6 \mathrm{~cm}$ diameter cylinder. Thickness of the antenna allows it to be bent very easily within the human skin tissue. Fig. 9 represents the S11 parameter of the antenna while bent condition and from the graph it is visible that it covers the ISM band though the return loss is quite low. As seen from Fig. 10, the VSWR of the antenna at bent condition is well below the 2 mark.

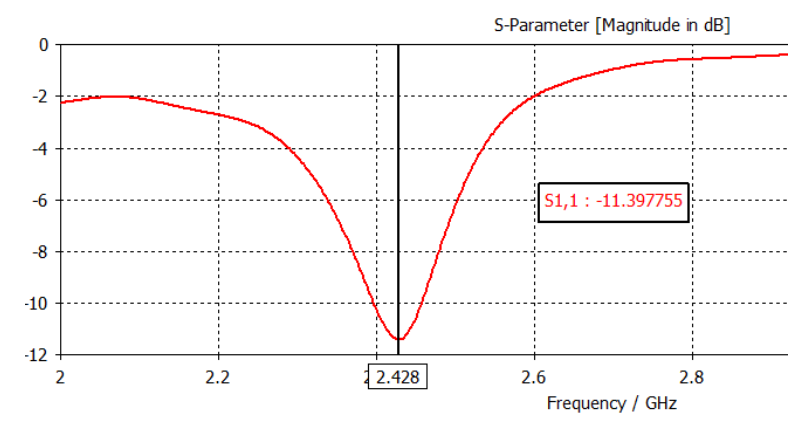

Fig. 9. S11 parameter of the antenna at Bent Condition

Fig. 9 represents the S11 parameter of the antenna while bent condition and from the graph it is visible that it covers the ISM band though the return loss is quite low. As seen from Fig. 10, the VSWR of the antenna at bent condition is well below the 2 mark.

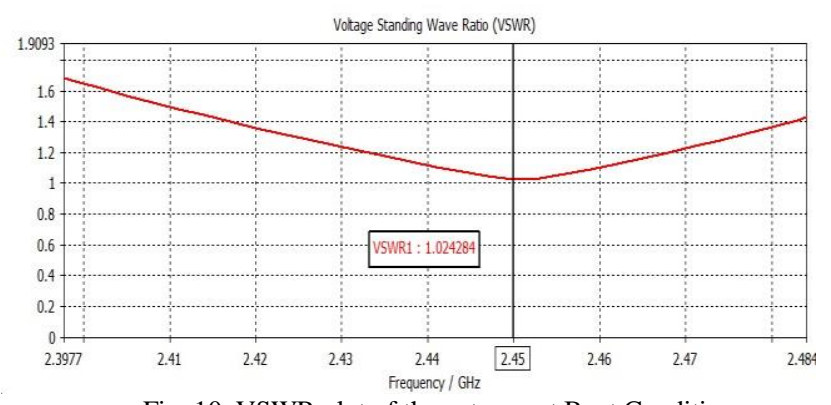

Fig. 10. VSWR plot of the antenna at Bent Condition

\section{E. Efficiency of the antenna}

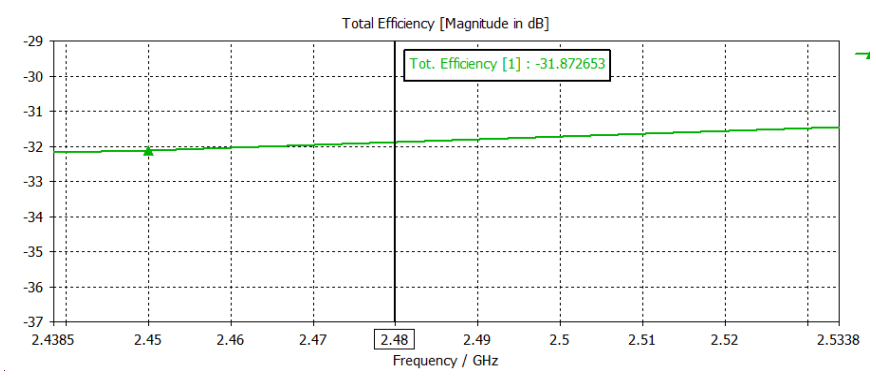

Fig. 11. Total Efficiency of the antenna inside Skin Tissue Model

From Fig. 11, we can observe that radiation efficiency of this antenna in planar condition is achieved around $-31.85 \mathrm{~dB}$ at the resonant frequency.

\section{F. Specific absorption rate and Thermal loss}

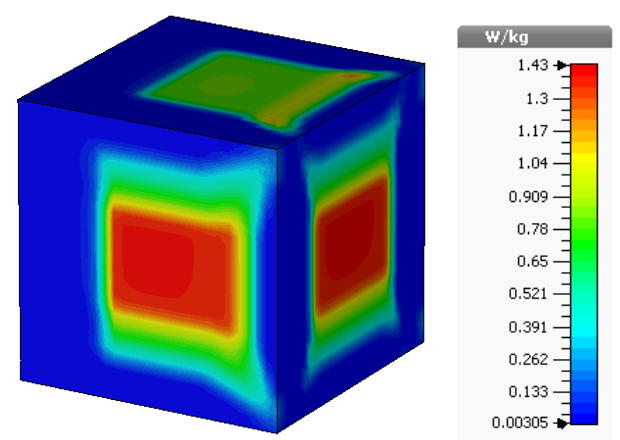

Fig. 12. 3D SAR Distribution subjected to $13.5 \mathrm{~mW}$ of input power

Specific Absorption Rate (SAR) is that parameter of antenna which measures the amount of radiation that is being observed by surrounding tissue. SAR should be under certain limiting value so that the radiation cannot harm human body. The standards for SAR calculation as regulated by IEEE/IEC 62704-1 standard states that the 10-g averaged SAR should not exceed $2 \mathrm{~W} / \mathrm{kg}$ as set by FCC and ICNIRP guidelines [23-24]. From Fig. 12, we can see that the peak value of SAR is $1.427 \mathrm{~W} / \mathrm{Kg}$ for an input power of $13.5 \mathrm{~mW}$ which is safe under safety regulations.

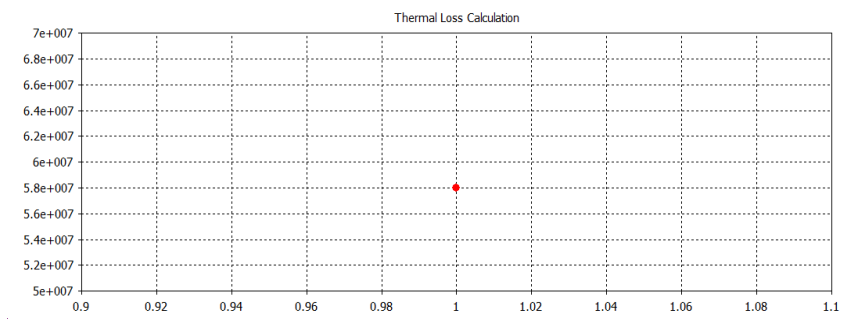

Fig. 13. Thermal Loss of the antenna inside Human Skin Tissue 
Sometimes thermal loss can be very high even with a lower SAR value which cannot be tolerated [25]. Fig. 13 shows the thermal loss calculation of this antenna which refelects a lower value of thermal loss.

\section{FABRICATION AND PRACTICAL RESULTS}

After completing the design in software, fabrication of the antenna was done for practical measurement. Due to unavailability of RogersR03010 and no facilitation of antenna fabrication in Bangladesh, mostly available Printed Circuit Board (PCB) was used for fabrication purpose. Copper was used as the patch material of the antenna. For the substrate, Fr4 was used since it was available. Fig. 14 shows the size comparison of the actual fabricated antenna with a coin and a ruler which clearly visualizes its dimension. In Fig. 14, the antenna is fitted with a SMA (Sub Miniature Version A) port. After that the antenna is connected to a network analyzer. The impedance of the network analyzer is matched with the impedance of the port at $50 \mathrm{ohm}$.

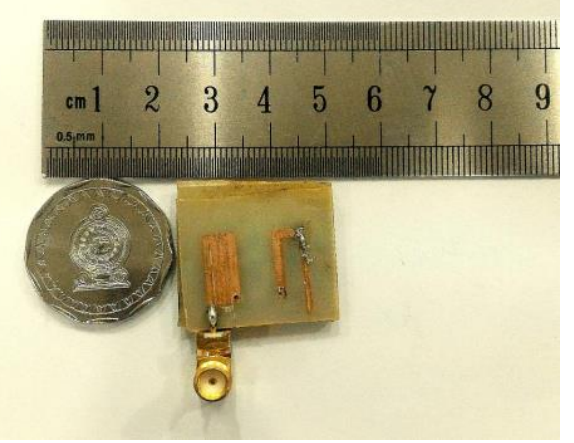

(a)

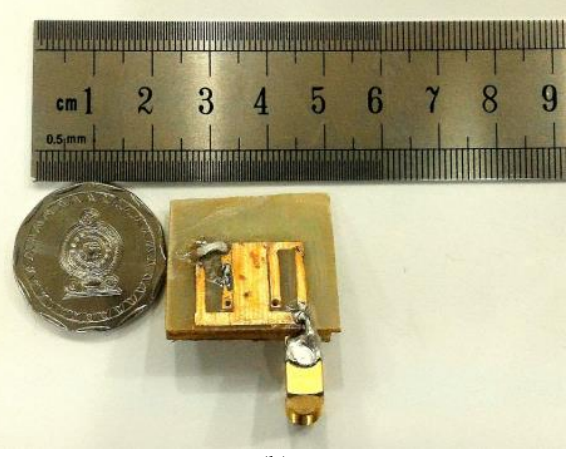

(b)

Fig. 14. Fabricated Antenna: (a) Top Layer, (b) Bottom Layer

\section{A. Experimental setup}

Fig. 15 shows the practical setup of the work.

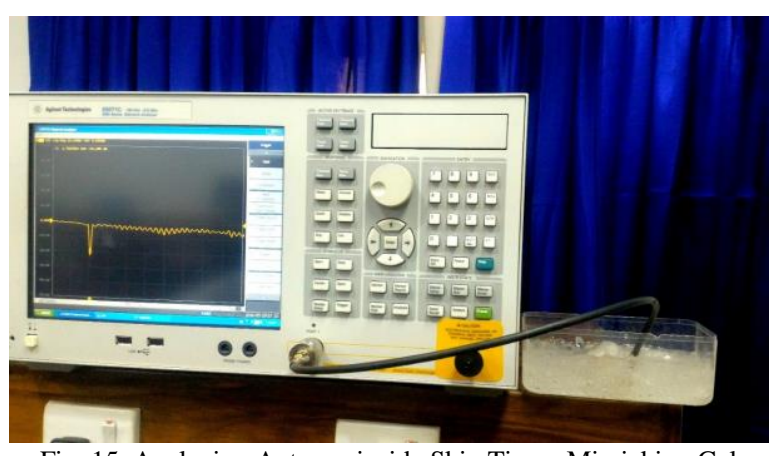

Fig. 15. Analyzing Antenna inside Skin Tissue Mimicking Gel
After connecting the antenna with the network analyzer, calibration was done successfully at first. Then the antenna performance is measured in free space. Finally, the antenna is encapsulated inside the human skin tissue gel to introduce the perfect practical scenario and S11 parameter of the antenna is observed.

\section{B. Result analysis}

Fig. 16 shows the performance of the antenna being measured inside skin tissue mimicking gel using network analyzer. It can be clearly seen from the picture that the resonant frequency is at about $1.52 \mathrm{GHz}$ without using the RogersR03010 block and the return loss of the antenna is about $-30 \mathrm{~dB}$. The resonant frequency is not exactly inside the ISM band because of not using the same material as simulation.

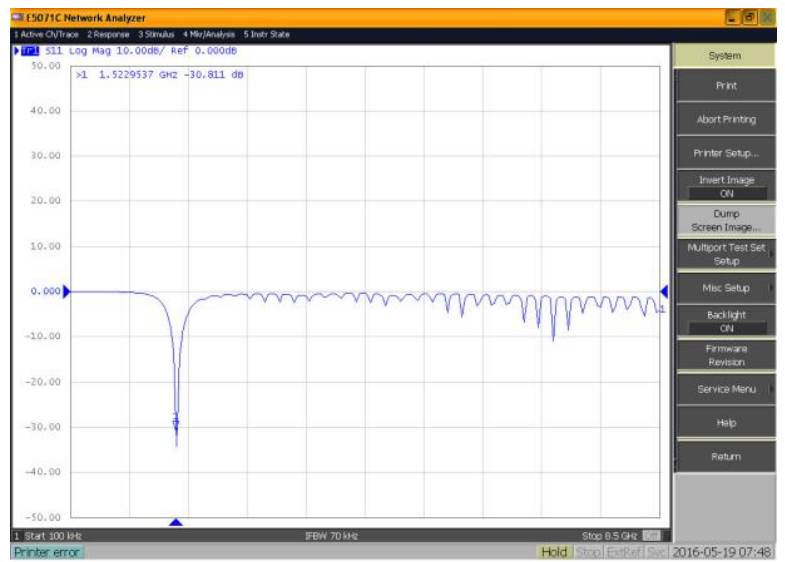

Fig. 16. Return Loss (S11) of the Antenna inside Skin Tissue Mimicking Gel

\section{COMPARISON ANALYSIS}

\section{A. Comparison analysis with different antennas}

Table $\mathrm{V}$ draws the comparison analysis in the aspect of antenna type, dimension, operating frequency, bandwidth and miniaturization method among the proposed antenna and several reported antennas. The proposed antenna in this paper exhibits a very small size compare to its counterparts.

TABLE V. SIZE COMPARISON OF DIFFERENT ANTENNAS

\begin{tabular}{|c|c|c|c|c|}
\hline References & $\begin{array}{c}\text { Antenna } \\
\text { Type }\end{array}$ & $\begin{array}{c}\text { Operating } \\
\text { frequency }\end{array}$ & $\begin{array}{c}\text { Dimensions } \\
\left(\mathbf{m m}^{\mathbf{3}}\right)\end{array}$ & $\begin{array}{c}\text { Miniatur- } \\
\text { ization } \\
\text { method }\end{array}$ \\
\hline$[11]$ & $\begin{array}{c}\text { Cavity } \\
\text { slot }\end{array}$ & $2.4 \mathrm{GHz}$ & 17.92 & $\begin{array}{c}\text { H-shaped } \\
\text { slot }\end{array}$ \\
\hline$[12]$ & PIFA & $\begin{array}{c}402 \mathrm{MHz} / \\
2.4 \mathrm{GHz}\end{array}$ & 135.45 & PIFA \\
\hline$[19]$ & PIFA & $\begin{array}{c}402 \mathrm{MHz} / \\
2.4 \mathrm{GHz}\end{array}$ & 3072 & PIFA \\
\hline$[26]$ & PIFA & $\begin{array}{c}402 \mathrm{MHz} / \\
2.4 \mathrm{GHz}\end{array}$ & 1265.63 & $\begin{array}{c}\text { Meandered } \\
\text { PIFA }\end{array}$ \\
\hline$[27]$ & Patch & $\begin{array}{c}402 \mathrm{MHz} / \\
2.4 \mathrm{GHz}\end{array}$ & 857.25 & $\begin{array}{c}\text { Split ring } \\
\text { resonator }\end{array}$ \\
\hline$[28]$ & PIFA & $\begin{array}{c}402 \mathrm{MHz} / \\
2.4 \mathrm{GHz}\end{array}$ & 534.48 & $\begin{array}{c}\text { Multi-layer } \\
\text { PIFA }\end{array}$ \\
\hline$[29]$ & PIFA & $\begin{array}{c}402 \mathrm{MHz} / \\
2.4 \mathrm{GHz}\end{array}$ & 691.52 & \begin{tabular}{c} 
Spiral PIFA \\
\hline$[30]$
\end{tabular} \\
\hline PIFA & $\begin{array}{c}402 \mathrm{MHz} / \\
2.4 \mathrm{GHz}\end{array}$ & 468.12 & $\begin{array}{c}\text { PIFA, open- } \\
\text { end slots }\end{array}$ \\
\hline Proposed & PIFA & $\mathbf{2 . 4 5 ~ G H z}$ & $\mathbf{5 4 . 3 5}$ & $\begin{array}{c}\text { Meandered } \\
\text { PIFA }\end{array}$ \\
\hline
\end{tabular}




\section{B. Comparison Analysis for Different Patch Materials}

Fig. 17 demonstrates the performance of the antenna for different patch materials. From the graph, we can see that for Aluminum patch, the resonant frequency doesn't fall under ISM band. But for Gold, Lead, Nickel and Platinum patch, the resonant frequency is well suited inside the ISM band. This performance increases the flexibility of using different patch materials according to suitability and availability.

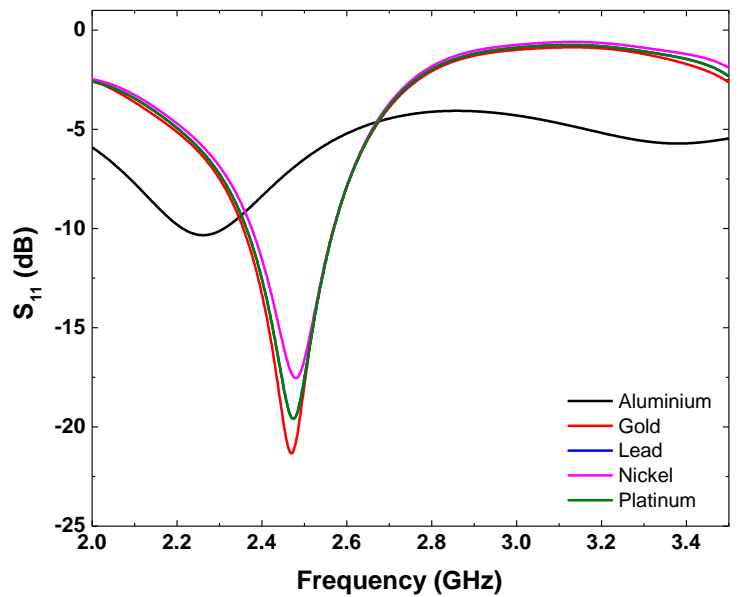

Fig. 17. Return Loss (S11) of the Antenna for Different Patch Materials

\section{Comparison Analysis for Different Substrate Materials}

Fig. 18 demonstrates the performance of the antenna for different substrate materials. From the graph, we can see that for Fr4 and Silicon, the resonant frequency doesn't fall under ISM band. But for Porcelain and RogersR0306, the resonant frequency is well suited inside the ISM band. This performance increases the flexibility of using different substrate materials according to suitability and availability.

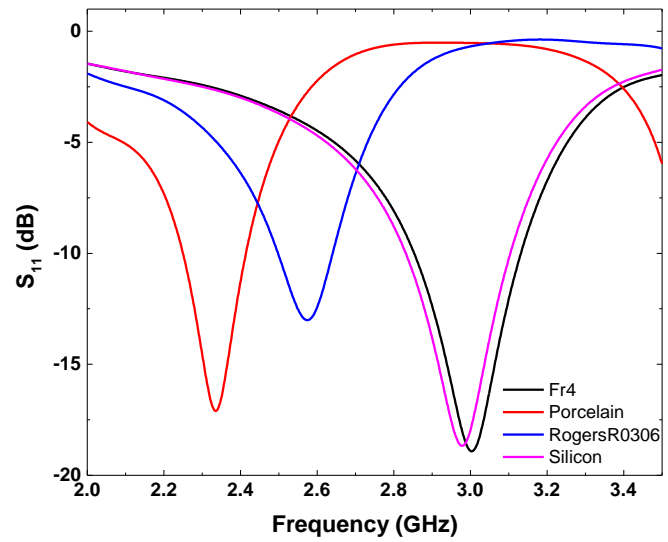

Fig. 18. Return Loss (S11) of the Antenna for Different Substrate Materials

\section{Comparison Analysis for Antenna inside Different \\ Human Tissue}

As this antenna is applicable for in body implantation, it is necessary for the antenna to work perfectly inside different human tissues for reliability. For proving the versatility of the antenna, we placed the antenna inside human Bone, Brain, Heart, Kidney, Liver, Lung, Muscle, Pancreas, Spinal Cord, Stomach, Teeth, and Trachea by maintaining the same dielectric value of original tissue at CST Microwave Studio. From Fig. 19, it can be seen that antenna works perfectly under ISM band inside almost each human tissue that we experienced.

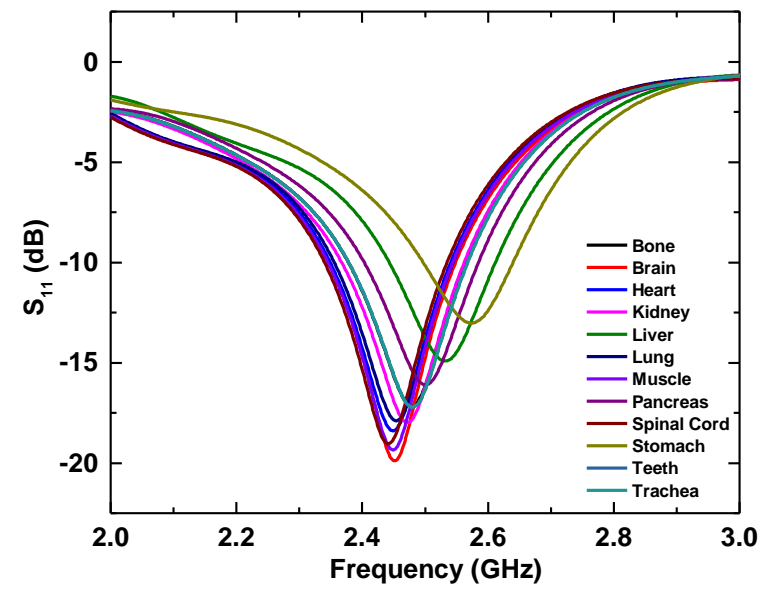

Fig. 19. Return Loss (S11) of Antenna inside Different Human Tissues

\section{E. Comparison Analysis of Antenna between planar and bent condition}

Fig. 20 represents the comaprison between S11 parameter in planar and bent conditions. In both conditions, the antenna works perfectly in ISM band though the resonant frequency has shifted a bit for bent condition.

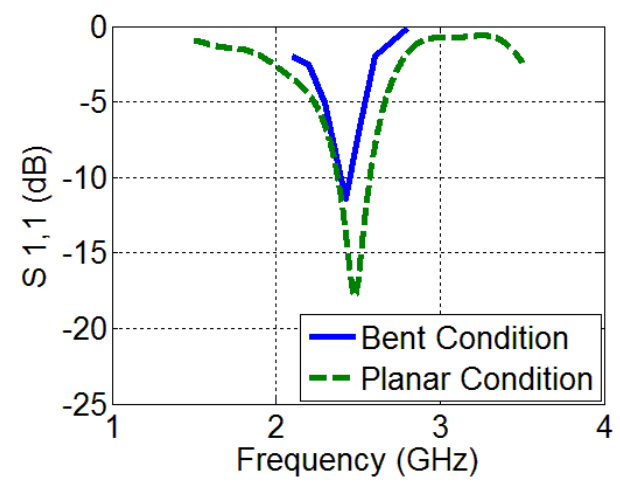

Fig. 20. Comparison of S11 parameter in Planar and Bent condition

\section{F. Comparison Analysis of Antenna between practical and simulated result}

Fig. 21 demonstrates the antenna performance in practical and simulation environment. The practical result slightly deviates from the desired resonant frequency due to scarcity of proper patch and substrate material.

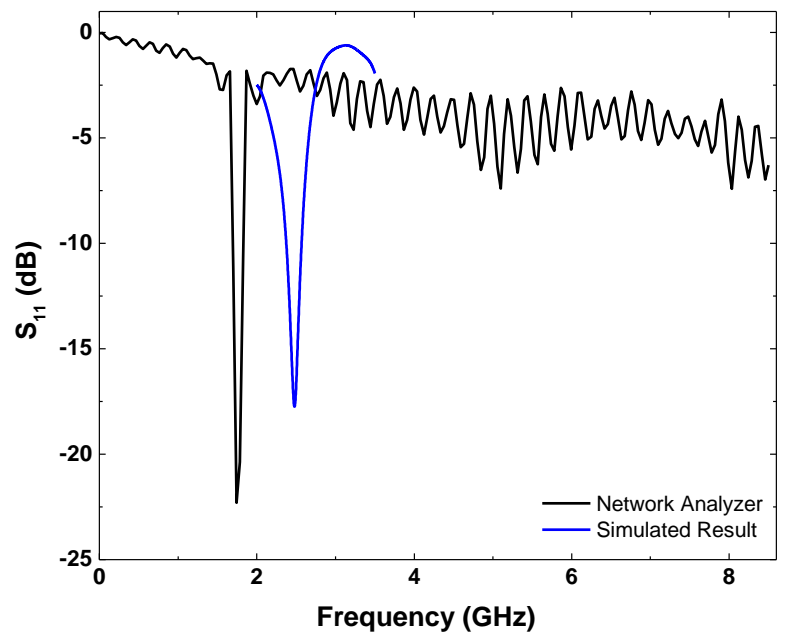

Fig. 21. Return Loss (S11) of Antenna in Simulation with Practical Case 


\section{Conclusions}

A miniaturized flexible meandered patch implantable PIFA antenna for Wireless Body Area Network (WBAN) operating at ISM Band is designed. The miniaturization is achieved by cutting slots and by introducing a novel top layer design, all while maintaining the resonant frequency at the ISM band. After completing the modeling part, the whole antenna was first inserted inside a biocompatible Rogers R03010 superstrate and then the whole encapsulated antenna was placed inside a one layer skin model to mimic an actual scenario of such implantation inside human body. All the performance measurements such as resonant frequency, far-field radiation pattern, total efficiency, SAR and thermal loss were then taken with the antenna inside the skin tissue model. After that, the antenna was subjected to bending and its performance parameters were again measured and compared with its planar condition. Then fabrication and measurement of the fabricated antenna was done by using network analyzer. One of the major limitation of this work relies in the proper fabrication of this antenna using same materials and size, which was not possible due to lack of resources. Furthermore, comparison analysis in different aspects have been shown. Some of the main points that can be drawn from this antenna are-

- Thin, tiny and bendable implantable design.

- High bandwidth and good return loss at $2.48 \mathrm{GHz}$ resonant frequency.

- Ability to bend without much change in its performance, meaning it has the possibility of taking the shape of a capsule like pill.

- $\quad$ SAR lower than the maximum limit regulated by IEEE/IEC 62704-1 standard.

Overall, the results indicates that the antenna exhibits all the performance parameters needed to be called implantable. Future work should include the implementation of a biomedical device using this antenna. Furthermore a total biomedical system can be incorporated with the antenna to test it out in a more real world scenario.

\section{REFERENCES}

[1] S. Zhang, Y. P. Qin, P. U. Mak, S. H. Pun, and M. I. Vai, "Real-time medical monitoring system design based on intra-body communication," Journal of Theoretical and Applied Information Technology, vol. 47, no. 2, pp. 649-652, 2013.

[2] T. Karacolak, R. Cooper, E. S. Ünlü, and E. Topsakal, "Dielectric properties of porcine skin tissue and in vivo testing of implantable antennas using pigs as model animals,"IEEE Antennas Wireless Propag. Lett., vol. 11, pp. 1686-1689, 2012.

[3] D. C. Garrett, B. A. Besler, J. Bourqui, E. C. Fear, and A. M. Setup, "Estimating Bulk Dielectric Properties of Biological Tissues at Microwave Frequencies," no. 1, pp. 2-3, 2016.

[4] F. Merli, B. Fuchs, J. R. Rosig, and A. K. Skrivervik, "The effect of insulating layers on the performance of implanted antennas,"IEEE Trans. Antennas Propag., vol. 59, no. 1, pp. 21-31, Jan. 2011.

[5] K. Agarwal and Y. Guo, "Interaction of Electromagnetic Waves with Humans in Wearable and Biomedical Implant Antennas," pp. 154-157, 2015.

[6] D. C. Sirait, Basari, F. Y. Zulkifli, and E. T. Rahardjo, "An implanted dipole antenna for RFID-based patient monitoring system," 2013 Int.
Conf. Qual. Res. QiR 2013 - Conjunction with ICCS 2013 2nd Int. Conf. Civ. Sp., pp. 142-145, 2013.

[7] W. Xia, K. Saito, M. Takahashi, and K. Ito, "Performances of an implanted cavity slot antenna embedded in the human arm," IEEE Trans. Antennas Propag., vol. 57, no. 4, pp. 894-899, Apr. 2009.

[8] Vorobyov, C. Hennemann, a. Vasylchenko, J. D. Decotignie, and J. Baumgartner, "Folded loop antenna as a promissing solution for a cochlear implant," 8th Eur. Conf. Antennas Propagation, EuCAP 2014, no. EuCAP, pp. 1735-1738, 2014.

[9] Z. Psenakova, M. Smondrk, J. Barabas, G. Lo Sciuto, and M. Benova, "Simulation and Assessment of Pacemaker RF Exposure ( 2.4 GHz ) by PIFA Antenna," pp. 569-573, 2016.

[10] M. K. Hosain, A. Kouzani, and S. Tye, "Multi-layer implantable antenna for closed loop deep brain stimulation system," 2012 Int. Symp. Commun. Inf. Technol. Isc. 2012, pp. 643-648, 2012.

[11] A. Al-Armaghany, B. Yu, T. Mak, K. F. Tong, and Y. Sun, "Feasibility study for future implantable neural-silicon interface devices," Proc. Annu. Int. Conf. IEEE Eng. Med. Biol. Soc. EMBS, pp. 3009-3015, 2011.

[12] Z. Duan, Y. X. Guo, M. Je, and D. L. Kwong, "Design and in vitro test of a differentially fed dual-band implantable antenna operating at MICS and ISM Bands," IEEE Trans. Antennas Propag., vol. 62, no. 5, pp. 2430-2439, 2014

[13] Gozasht, F., \& Mohan, A. S. (2013). Miniaturized Slot PIFA Antenna for Tripleband Implantable Biomedical Applications, 2, 2-4.

[14] Gozasht, F. (2013). Miniaturized E-Shaped PIFA Antenna for Wideband Implantable Biomedical Applications, 832-835.

[15] Alptekin, D., Alatan, L., \& Genc, N. G. (2008). DUAL BAND PIFA DESIGN FOR BIOMEDICAL APPLICATIONS.

[16] Bouazizi, A., Nasri, N., Zaibi, G., Samet, M., \& Kachouri, A. (2015). A Novel Implantable Planar Inverted-F Antenna for Biomedical Applications, 1-6.

[17] H. Usui, M. Takahashi, and K. Ito, "Radiation characteristics of an implanted cavity slot antenna into the human body," in Proc. IEEE Antennas and Propag. Soc. Int. Symp., Albuquerque, NM, 2006, pp.1095-1098.

[18] J. L. Buckley, K. G. McCarthy, L. Loizou, B. O'Flynn, and C. O'Mathuna, "A Dual-ISM-Band Antenna of Small Size Using a Spiral Structure With Parasitic Element," IEEE Antennas Wirel. Propag. Lett., vol. 15, no. c, pp. 630-633, 2016.

[19] J. Kim and Y. Rahmat-Samii, "Implanted antennas inside a human body: Simulations, designs, and characterizations," IEEE Trans. Microw. Theory Tech., vol. 52, no. 8, pp. 1934-1943, Aug. 2004.

[20] Raghavan, S., \& Jayanthi, N. (2009). Design of planar inverted -F antenna for wireless applications. WSEAS Transactions on Communications, 8(8), 863-872.

[21] Sheet, D. (n.d.). RO3000 ® Series Circuit Materials.

[22] S. Gabriel, R. W. Lau, and C. Gabriel, "The dielectric properties of biological tissues,” Phys. Med. Biol. pp. 2231-2293, Oct. 2004 [Online]. Available: http://niremf.ifac.cnr.it/tissprop/, (1996)

[23] Safety, E., Committee, S. C., Radiation, N., \& Board, I. S. (2008). IEEE Recommended Practice for Measurements and Computations of Radio Frequency Electromagnetic Fields With Respect to Human Exposure to Such Fields , $100 \mathrm{kHz}-300 \mathrm{GHz}$. Measurement (Vol. 2002).

[24] ICNIRP, "Guidelines for limiting exposure to timevarying electric, magnetic, and electromagnetic fields," Health Phys., vol. 74, pp. 4945229, 1998

[25] S. Caporal Del Barrio, G. F. Pedersen, and A. S. Morris III, "Thermal loss becomes an issue for narrow-band tunable antennas in fourth generation handsets," IET Microwaves, Antennas Propag., vol. 9, no. 10, pp. 1015-1020, 2015.

[26] T. Karacolak, A. Z. Hood, E. Topsakal, "Design of a dual-band implantable antenna and development of skin mimicking gels for continuous glucose monitoring." IEEE Trans. Microw. Theory Tech., Vol.56, pp. 1001-1008, Apr 2008.

[27] C.J. Sánchez-Ferna'ndez, O. Quevedo-Teruel, J. Requena-Carrión, L. Incla'n-Sa'nchez, E. Rajo-Iglesias, "Dual-band microstrip patch antenna based on short-circuited ring and spiral resonators for implantable medical devices." IET Microwaves, Antennas Propag., vol.4, no.8, pp. 1048-1055, 2010.

[28] F. Merli, L. Bolomey, J.-F. Zürcher, G. Corradini, E. Meurville and A.K. Skrivervik, "Design, realization and measurements of a miniature 
antenna for implantable wireless communication systems," IEEE Trans. on Antennas and Propagat., vol. 59, no. 10, pp. 3544-3555, Oct. 2011.

[29] C. Liu, Y. X. Guo, and S. Xiao, "Compact dual-band antenna for implantable devices," IEEE Antennas and Wireless Propag. Lett., vol. 11, pp. 1508-1511, 2012.

[30] L.J. Xu, Y.X. Guo, W. Wu, "Dual-Band Implantable Antenna with Open-End Slots on Ground," IEEE Antennas and Wireless Propag. Lett., vol. 11, pp. 1564-1567, 2012.

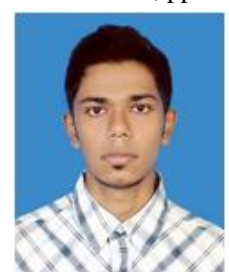

Nasim Al Islam received his B.Sc. and M.Sc. in Electrical and Electronic Engineering (EEE) degree from American International UniversityBangladesh (AIUB) in September 2015 and October 2016 respectively. $\mathrm{He}$ is currently working as a Lecturer for the Department of EEE, Faculty of Engineering at AIUB. He is an active IEEE member \& volunteer for last 4 years and a

member of IEEE MTTS (Microwave Theory and Techniques Society). His research interest includes RF and Wireless communication systems, biomedical devices and implantable antenna.

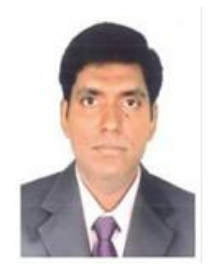

Farhadur Arifin received his B.Sc. Degree in Electrical and Electronic Engineering from Bangladesh University of Engineering and Technology (BUET), Dhaka, Bangladesh in 2000 and M.Sc. Degree in Electrical Engineering from Royal Institute of Technology (KTH), Stockholm, Sweden in 2005. Currently he is working as an Assistant Professor in the department of Electrical and Electronic Engineering at American International UniversityBangladesh (AIUB). He has two years of research experience related to reliability in embedded systems in the department of Electronics and information systems (ELIS) in University of Ghent, Belgium and one year of research experience related to multiprocessor system on chip design in University of Erlangen-Nuremburg, Germany. His research interests include ultra-wide-band (UWB) technology in wireless communications, UWB antennas, System on chip design, RF integrated circuit and biomedical applications 